\title{
Reflecting on the Japan-Chile Task-Based Telecollaboration Project for Beginner-Level Learners
}

\section{B. Greg Dunne}

Using O'Dowd and Ritter's (2006) Inventory of Reasons for Failed Communication in Telecollaborative Projects as a barometer, this article details the considerations and procedures followed in a task-based, asynchronous email telecollaboration project between EFL (English as a Foreign Language) learners in Japan and Chile. In a climate where current research surrounding telecollaboration continues to gravitate toward the dual foci of intercultural communicative competence and multimodal technology, this article exemplifies how the adoption of a task-based framework can greatly assist the induction of beginner-level EFL students into a telecollaborative learning environment. It also encourages EFL and ESL (English as a Second Language) teachers throughout the world to seek task designs that will help them do the same. The project experienced its share of logistical and technical challenges but by adopting the currently unconventional stance of designing tasks that highlight individual identity and downplay cultural identity the project appeared to minimize intercultural tension, unmanageable levels of incomprehensibility and inability to arrive at task outcomes.

Utilisant l'article de O'Dowd et Ritter (2006) Inventory of Reasons for Failed Communication in Telecollaborative Projects comme baromètre, cet article décrit en détail les considérations et les procédures d'un projet de télécollaboration asynchrone, par courriel et basé sur les tâches entre des apprenants d'anglais langue étrangère (ALE) au Japon et au Chili. Dans le climat actuel où la recherche portant sur la télécollaboration continue à se tourner vers la compétence communicative interculturelle et la technologie multimodale, cet article démontre les bienfaits significatifs d'adopter un cadre basé sur les tâches pour accueillir les élèves débutants en ALE dans un milieu d'apprentissage télécollaboratif. L'article encourage également les enseignants d'ALE et d'ALS partout au monde à rechercher des tâches qui les aideront à en faire autant. Le projet a connu sa part de défis logistiques et techniques, mais en adoptant la position originale de concevoir des tâches qui soulignent l'identité individuelle et diminuent l'identité culturelle, il semble avoir minimisé la tension interculturelle, l'incompréhensibilité et l'incapacité à arriver aux résultats voulus.

This article reports on a task-based telecollaboration project between beginner-level EFL learners in Japan and Chile. The report is written from the perspective of the teacher of the Japanese class, respecting that the Chilean 
teacher's time and workload constraints prevented her from participating in joint post-project reflection. The Inventory of Reasons for Failed Communication in Telecollaborative Projects from O'Dowd and Ritter (2006) was used to reflect on specific aspects of the project that contributed to the overall outcome. By using a "twinning" model of telecollaboration and by sequencing achievable tasks designed to inspire curiosity and surprise, beginner-level language learners could experience intercultural telecollaborative opportunities free of communication breakdown. Furthermore, by the adoption of the currently unconventional stance of designing closed tasks that highlight individual identity and downplay cultural identity, the project appeared to minimize intercultural tension, unmanageable levels of incomprehensibility, and inability to arrive at task outcomes.

\section{Review of the Literature}

The new millennium has witnessed significant growth in the number of telecollaboration projects in language education, which has understandably spawned a steadily growing body of dedicated literature, including several edited book volumes (e.g., Belz \& Thorne, 2006; Guth \& Helm, 2010; O’Dowd, 2007). Guth and Helm (2010) define telecollaboration as "Internet-based intercultural exchange between people of different cultural/national backgrounds, set up in an institutional context with the aim of developing both language skills and intercultural communicative competence" (p. 14). During the early 21st century, two main models of telecollaboration emerged, tandem and twinning. O'Rourke (2007) defines tandem exchanges as "reciprocal support and instruction between two learners, each of whom is a native speaker of the other's target language" (p. 43). Conversely, twinning (Miguela, 2007) employs a lingua franca. Both models allow for either synchronous (i.e., real-time) or asynchronous telecollaboration.

The current research landscape predominantly focuses on either the development of intercultural (communicative) competence (ICC; e.g., Belz, 2007; Byram, 1997; Hauck, 2010; Jauregi \& Banados, 2010; Müller-Hartmann, 2006; Rathje, 2007; Ware, 2005) or the advantages of the multimodal use of combined technologies, (e.g., Hampel, 2006; Hauck, 2010; Stockwell, 2010). In both instances the subjects are usually advanced learners of English. With regard to lower level learners, case studies from Japan and other Expanding Circle (Jenkins, 2009; Kachru, 1988) EFL contexts have slowly been emerging, reporting on accounts of telecollaboration through Skype (e.g., Meguro \& Bryant, 2010; Tian \& Wang, 2010), Facebook (e.g., Aoki \& Kimura, 2009), and moodle-based discussion forums (e.g., Chase \& Alexander, 2007). In response to an identified gap in the literature, the present project utilizes the Task-Based Language Teaching (TBLT) framework first outlined in Willis (1996) and critiques the project utilizing the O'Dowd and Ritter (2006) inventory. 


\section{Project Description and Methodology}

The telecollaborative task project was intended to engage the learners in authentic and meaningful real-world (Willis \& Willis, 2007) international communication that would necessitate English as a lingua franca (Jenkins, 2009; Seidlhofer \& Widdowson, 2009) within asynchronous (Warschauer \& Healey, 1998) e-mail exchanges. In order to maintain the continuity of e-mail exchange, the teachers' first challenge was to design a telecollaborative task project that students would perceive as interesting, nonthreatening, and doable. In order to be doable, not only did the project need to have the students navigate the technology and compose messages satisfying the conventions of intelligibility, comprehensibility, and interpretability (Smith, 2009), but the project also required the learners to be able to envisage and achieve task outcomes (Willis \& Willis, 2007).

The university students from Japan $(n=36)$ and Chile $(n=36)$ participated in tasks (Robinson, 2011; Samuda \& Bygate, 2008; Willis \& Willis, 2007) that, if stripped of their Computer Assisted Language Learning (CALL) element, would resemble regular TBLT lessons observable in homogeneous EFL classrooms. The Japanese students were first-year English language majors at a women's university in Osaka, Japan. They had one 90-minute writing class per week to work on the project, which was designed to complement the self-introduction unit of their process-writing textbook (see Table 1). Of the 36 first-year liberal arts students from Chile, 31 were female and 5 were male. Although they were allotted two 60-minute Computer Mediated Communication classes per week, only one of those was in a computer room.

The project's design guaranteed a minimum exchange of six e-mails, three from each partner. At the beginning of the project, each Japanese student mailed her partner a letter of introduction with a photo attachment. However, with the intention of generating intrigue, the photo depicted three students and invited the Chilean partner to send five questions to help her guess which of the three her Japanese partner was. Popular questions included "What are you wearing?" and "Are you the tallest?" In order to sustain intrigue and counter premature closure of the task through questions such as "Are you the student in the middle?", the Japanese student's reply informed her partner that only four of her five answers were true. The Japanese students were arranged in support groups of three, and each trio then pooled their 15 answers about their partner trio, creating a within-class collaborative activity. Because the Chilean students similarly sent mail and digital photos challenging their Japanese partners to guess their identities, this within-class support group system was recommended to the Chilean teacher but not implemented, as it was deemed impractical in that setting. The remaining exchanges between the Japanese and Chilean students did not adhere to a structured format; instead, students were granted greater autonomy over how and what they wrote. 
Table 1

Overview of the Telecollaboration Project

\begin{tabular}{lll}
\hline & Japan & Chile \\
\hline Original \# of students & 37 (all female) & 37 (32 female, 5 male) \\
Ultimate \# of students & 36 (all female) & 36 (31 female, 5 male) \\
Course curriculum type & Writing & Computer Mediated Communication \\
Academic Calendar & 3 weeks behind & 3 weeks ahead \\
Model & TBLT + 'Twinning' combined with 3-person within-class collabora- \\
& tive groups & \\
Task projects & Self introduction (Guess who I am). Completed \\
& Family \& friends (Read \& draw). Discarded \\
Platform & ePals & ePals \\
\hline
\end{tabular}

\section{Discussion: Inventory of Reasons for Failed Communication in Telecollaborative Projects}

O'Dowd and Ritter's (2006) inventory systematically classifies 10 common areas of potential or previously documented failure into four overarching levels, but O'Dowd and Ritter are mindful to repeatedly emphasize that there is a significant degree of interconnectivity among them. The four levels are the individual, the classroom (or methodological), the socioinstitutional, and the interaction.

\section{The Individual Level}

There are two areas at the individual level of the inventory: (a) the learner's current level of intercultural communicative competence and (b) the learner's motivation and expectations.

The learner's current level of intercultural communicative competence (ICC). Byram (1997) contends that a learner's inclination to challenge both herself and the culture she communicates with indicates a high degree of ICC. Should this be the case, the Japanese learners who participated in this project should be regarded as having low ICC, as they had negligible degrees of prior experience in intercultural communication. According to O'Dowd (2006), a lack of such experience jeopardizes the possibility of learners possessing sufficiently developed skills of discovery and interaction for operating at an adequate level of ICC in ethnographic interview tasks. Accordingly, simple closed tasks were preferred for the current project. Specifically, the early e-mail exchanges needed to be suitably formulaic (see Appendices A and B) to safeguard against students inadvertently causing offense or misunderstanding in their correspondence. Consequently, each student's initial e-mail conformed to a teacher-composed form letter/cloze passage (MüllerHartmann, 2007, p. 179). The form letter structure was designed to safeguard against problems arising from the Japanese students not having sufficiently developed levels of ICC. It was also intended to include a sufficient quantity 
and quality of cloze options for their attention to be directed toward comprehension of the text and subsequently make informed and somewhat autonomous lexical decisions. The Chilean teacher reported that her students had had few previous intercultural experiences and agreed to also adopt the form letter structure for introductory e-mails.

The learner's motivation and expectations. It is crucial for both sides of the telecollaboration partnership to firmly establish what each partner expects of the other. Ware (2005) specifies disparate perceptions and efforts surrounding grammatical accuracy, message length, and response time as three common causes of telecollaborative breakdown. In the current project, the form-letter/ cloze-passage structure ensured that each student's introductory e-mail and resulting reply were roughly uniform in length and sufficiently grammatically accurate.

Breakdown in project continuity resulting from response time issues proved more difficult to safeguard against. The objective here was to minimize the chance that some students might become demotivated if they were among a few to not receive mail on time. The Chilean class met in their computer room on Thursdays. It was subsequently intended that they send mail during their allotted computer-mediated communication (CMC) class each Thursday, and the Japanese students would reply approximately 12 hours later during their Friday morning class. Apart from response time issues emerging at a micro level with turnaround time being measurable in hours, issues also emerged at a macro level when the flow of exchange was interrupted due to misaligned academic calendars and cultural or religious holiday periods. Both Easter (Chile) and Golden Week vacation (Japan) occurred in the early weeks of the project, resulting in both classes having to wait a week longer than usual to receive replies to their e-mails. Conversely, had the project begun after these holiday periods, it would have clashed with the assessment week in Chile.

\section{The Classroom (Methodological) Level}

O'Dowd and Ritter (2006) list five areas at the classroom level of their inventory. These are (a) teacher-teacher relationship, (b) task design, (c) learnermatching procedures, (d) local group dynamics, and (e) the pre-exchange briefing.

The teacher-teacher relationship. This area of the inventory emphasizes the need for teachers to remain aware that telecollaboration is a form of teamteaching, and warns us that teachers often develop a propensity for not divulging all of their plans to their partner teacher. Therefore, mindful of the need for instructional clarity and transparency, the teachers piloted the project using each other as partners, in addition to their regular e-mail exchange.

Telecollaboration partnerships are subject to the conventions of a genre that is cultivated as the project itself unfolds and the interpersonal relationships within it develop. This said, both teachers began the project with like- 
minded objectives, but their individual objectives started to evolve differently due to their own students' needs. In particular, the Chilean class wanted to spend more time using their computers than the project required. This did not hinder the project but was enough to prevent a subsequent project.

The task design. The renowned TBLT concept of learning-by-doing was the impetus behind the design of the Japanese side of the project. Specifically, since these students' international English communication rarely extended beyond speaking to their teacher, the project intended them to experience L2 communication and negotiate closed task outcomes (Willis \& Willis, 2007) in as close to a real-world context as possible. Because the term task can be interpreted in several ways, in the current project its nuance was drawn from the well-known Willis (1996) TBLT framework. This framework consists of a pretask, main task, report, and posttask cycle of stages.

Whereas the Chilean teacher simply viewed the project as a telecollaborative exchange, the teacher of the Japanese class viewed the merger of telecollaboration and tasks as engendering greater potential. Consequently, the respective teachers were free to conduct their lessons however they chose at the intraclass level. On the Japanese side of the exchange, the project engaged the students in pretask exercises that prompted them to consider the meaning and form to be used in the main task of composing mail. As an example of pretask design, the seven clauses constituting the opening paragraph of the introductory form letter were jumbled. Students then collaborated in groups of three to correctly reorder the clauses into a coherent passage. The subsequent posttask comprised cloze exercises based on the introductory passage. Since the second task required students to compose five questions, its pretask presented students with a set of sample questions with scrambled word order. By unscrambling and reformulating, students focused on the form of relevant question types. Finally, the posttask consisted of a running dictation based on the opening paragraph of the e-mail message (see Appendix B). In this posttask, each group of three students constituted a relay team. Student A of each team read and remembered as much of the text as possible, then ran and wrote it as accurately as she could on a sheet of paper several metres away. She then returned and informed Student B where she had left off in the text. Student B then remembered as much as she could and raced to the distant sheet of paper to continue the text's transcription, and so on. The first group to accurately transcribe the complete text claimed victory.

Learner matching procedures. Language proficiency (Belz, 2002b; Hauck \& Youngs, 2008; Lee, 2004) and age (Belz, 2002a; Hauck \& Youngs, 2008; Lee, 2004) have long been regarded as important considerations when matching learners. In the current project, gender was also taken into consideration, so the teacher of the Japanese students optimally sought university student partners who were of similar language proficiency, age, and gender. The inclination here was that the more the partners had in common, the greater the likelihood that they would identify and co-operate with each other. 
The fact that five Chilean students were male did not prove problematic. For the identity-guessing task to work in those instances, the Chilean students simply recruited male students from other groups for their photo shoot.

Local group dynamics. Prior to the commencement of the English program, the Japanese students sat for a placement test, which ranked their general language ability in relation to one another. Accordingly, when the decision was made to arrange them in support groups of three, the groups were configured so that they each included a high-, middle-, and low-scoring student. In this way, weaker students always had intragroup access to peer assistance from stronger students. The Chilean class were unable to formulate their groups this way, as they had no placement test rankings to refer to.

Pre-exchange briefing. On the Japanese side, an ambitious attempt was made to expedite the process of familiarizing all students with the project's objectives, procedures, and technology. This stemmed from time constraints compounded by freshman orientation weeks, Easter, Golden Week, and the fact that the Chilean academic year had begun three weeks ahead of Japan's. In order to not further inconvenience the Chilean students, the Japanese students were given a 45-minute session outlining the project. Following the issuance of the students' Chilean partners' names and ePal mail addresses, teacher-guided drafting of the students' introductory messages, the snapping of digital photographs and forwarding of these from their cell-phone cameras to their university e-mail accounts, the teacher demonstrated how to use the ePals mail accounts.

\section{The Socioinstitutional Level}

O'Dowd and Ritter (2006) list three areas at the socioinstitutional level. These are (a) the technology used, (b) the general organization of the students' course of study, and (c) differences in prestige values of cultures and languages.

The technology. It is commonplace for course management systems (CMS) to be used for forum-based projects (e.g., Chase \& Alexander, 2007; Markey, 2007). Although CMS may also accommodate teacher-monitored, attachmentsupported e-mail exchanges between individuals, the preferred conduit for the current project was the free e-mail platform available from the ePals.com website.

EPals.com offers many free services, but only the partner search and userfriendly e-mail system were deemed useful. Each teacher obtained a free ePal e-mail account and, within that, created 36 subsidiary "monitored mail" accounts for student use. If the teacher so desired, all incoming and outgoing mail could therefore be read, censored, edited, or blocked before reaching its destination.

Hampel (2006) highlights the difficulties learners can have in acclimatizing to sophisticated (multimodal in her instance) technology. She declares that to derive maximum language practice from this technology, learners face the added burden of electronic literacy, which often conflicts with their intrin- 
sic approaches to learning. In the synchronous environment of her case study, she found that stronger students dominated both oral and textual tasks at great expense to weaker students. As this warning was heeded in the current task project, it appears the adoption of asynchronous tasks within the TBLT framework of the project is further justified. Unlike when students compete to post and reply in online forums, all students in the current project were afforded equal opportunity to process input and produce output, and do so at a learning pace that they self-determined.

The general organization of the students' course of study. As previously noted, the misaligned academic calendars between Japan and Chile placed constraints on the project's continuity. Conversely, the decision of both teachers not to assess their students on this pilot project, intended to engender positive attitudes toward real-world communication in English, likely resulted in the avoidance of much unnecessary anxiety.

The differences in prestige values of cultures and languages. Problematic exchanges associated with disparate prestige values of the language being studied were reported in a German-American context by Ware (2005). Problems associated with cultural stereotyping in a Spanish-American context have been reported by O'Dowd (2005) and in a Palestinian-Italian context by Helm, Guth, and Farrah (2012), although the latter more optimistically purports that conflict is merely another opportunity for learning. In the first two instances, a tandem model (O'Rourke, 2007) was utilized and, in the third instance, synchronous (i.e., real-time) audio and videoconferencing were used. In contrast, the current project employed an asynchronous, twinning design for the Japan-Chile exchanges. Consequently, the use of the common single target language as a lingua franca between two groups of beginner-level learners eradicated any native/non-native speaker discrepancy. Furthermore, because the project opted to employ closed tasks characterized by ample scaffolded text, teacher monitoring of freely written text, a set sequence of e-mail, and closed task outcomes (i.e. either correct or incorrect guesses), students were far less likely to contravene the values of their partners in the way that were found to occur by Reeder, Macfadyen, Roche, and Chase (2004) among beginner-level students, who participated in online bulletin board communication.

\section{The Interaction Level}

The final single-area level of O'Dowd and Ritter's (2006) Inventory of Reasons for Failed Communication in Telecollaborative Projects concerns potential tension resulting from pragmatic differences. Although the students were not required to formally evaluate the project, no instances of intercultural pragmatic tension were reported or observed. In fact, the teacher of the Japanese students was so intent on avoiding it, especially in the earliest exchanges, that it greatly influenced both the task design and the choice of technology. Specifically, the use of a cloze skeleton for the letter of introduction, pretask exercises designed to simplify and rehearse message composition, and the monitored 
mail feature inherent in the ePals system are all aspects of the project that were considered successful in minimizing pragmalinguistic breakdown.

\section{Conclusion}

This article has narrated the considerations and procedures adopted in a first-time telecollaboration project for all participants and critiqued them with regard to O'Dowd and Ritter's (2006) Inventory of Reasons for Failed Communication in Telecollaborative Projects. In a climate where current research surrounding telecollaboration continues to gravitate toward the dual foci of intercultural communicative competence and increasingly sophisticated multimodal technology, it has been argued that the prospect of inducting beginner-level EFL students into a telecollaborative environment need not be daunting. The fact that all participating students achieved a task outcome by the completion of the project hopefully will serve to encourage language teachers from other contexts, including ESL teachers in countries such as Canada, to embrace telecollaboration as an opportunity not exclusive to advanced EFL students conducting open tasks.

The project experienced its share of logistical and technical challenges, as appears to be the case with all rigorously conducted telecollaboration case studies that have been reported in telecollaboration-related literature. However, these challenges are best viewed as valuable learning experiences that can only benefit future projects. Some of the plans and decisions that went into the project constitute features that are either rarely used or, indeed, unique. Specificially, the project utilized task-based cycles and closed tasks, and prioritized individual identity over cultural identity. With regard to identity, Candlin $(1989$, p. 3) reminds us that, in the process of language learning, it is more important to focus on the learner's individual identity vis-à-vis social or cultural identity.

It is believed that the project was a positive experience for the participating students. At no time under the implementation of a closed TBLT design was any intercultural tension, unmanageable levels of incomprehensibility, or inability to arrive at a task outcome observed or reported. Furthermore, O'Dowd and Ritter's (2006) inventory proved to be a valuable reflective tool for identifying the project's strengths and shortcomings. As a result of the project, two EFL classes of beginner-level learners have now interacted with the world, and it is hoped that their experience will inspire similar EFL classes to embark on similar experiences.

\section{The Author}

B. Greg Dunne is currently an Associate Professor in the International English department at Osaka Shoin Women's University, Japan. He holds a Master's in applied linguistics (TESOL) degree from Macquarie University. He has published in several subfields of TESL, including task-based learning, CALL, teacher development, testing, and world Englishes. 


\section{References}

Aoki, K., \& Kimura, M. (2009). Telecollaboration 2.0: Using Facebook for intercultural exchange. In C. Siemens \& C. Fulford (Eds.), Proceedings of the World Conference on Educational Multimedia, Hypermedia and Telecommunications (pp. 135-144). Chesapeake, VA: AACE.

Belz, J. A. (2002a). The myth of the deficient communicator. Language Teaching Research, 6(1), 59-82.

Belz, J. A. (2002b). Social dimensions of telecollaborative foreign language study. Language Learning \& Technology, 6(1), 60-81.

Belz, J. A. (2007). The development of intercultural communicative competence in telecollaborative partnerships. In R. O'Dowd (Ed.), Online intercultural exchange: An introduction for foreign language teachers (pp. 127-166). Clevedon, UK: Multilingual Matters.

Belz, J. A., \& Thorne, S. L. (Eds.). (2006). Internet-mediated intercultural foreign language education. Boston, MA: Heinle.

Byram, M. (1997). Teaching and assessing intercultural communicative competence. Clevedon, UK: Multilingual Matters.

Candlin, C. N. (1989). Language, culture and curriculum. In C. N. Candlin \& T. F. McNamara (Eds.), Language, learning and community: Festschrift in honour of Terry R. Quinn (pp. 1-24). Sydney, Australia: Macquarie University.

Chase, C., \& Alexander, P. (2007). The Japan-Korea culture exchange project. In R. O'Dowd (Ed.), Online intercultural exchange: An introduction for foreign language teachers (pp. 259-263). Clevedon, UK: Multilingual Matters.

Guth, S., \& Helm, F. (Eds.). (2010). Telecollaboration 2.0: Language, literacies and intercultural learning in the 21st century. Bern, Switzerland: Peter Lang.

Hampel, R. (2006). Rethinking task design for the digital age: A framework for language teaching and learning in a synchronous online environment. ReCALL, 18(1), 105-121.

Hauck, M. (2010). Telecollaboration: At the interface between multimodal and intercultural communicative competence. In S. Guth \& F. Helm (Eds.), Telecollaboration 2.0: Language, literacies and intercultural learning in the 21st century (pp. 219-248). Bern, Switzerland: Peter Lang.

Hauck, M., \& Youngs, B. L. (2008). Telecollaboration in multimodal environments: The impact on task design and learner interaction. Computer Assisted Language Learning, 21(2), 87-124.

Helm, F., Guth, S., \& Farrah, M. (2012). Promoting dialogue or hegemonic practice? Power issues in telecollaboration. Language Learning \& Technology, 16(2), 103-127.

Jauregi, K., \& Banados, E. (2010). An intercontinental video-web communication project between Chile and the Netherlands. In S. Guth \& F. Helm (Eds.), Telecollaboration 2.0: Language, literacies and intercultural learning in the 21st century (pp. 427-436). Bern, Switzerland: Peter Lang.

Jenkins, J. (2009). Exploring attitudes towards English as a lingua franca in the East Asian context. In K. Murata \& J. Jenkins (Eds.), Global Englishes in Asian contexts: Current and future debates (pp. 40-56). Basingstoke, UK: Palgrave Macmillan.

Kachru, B. B. (1988). The sacred cows of English. English Today, 4(4), 3-8.

Lee, L. (2004). Learners' perspectives on networked collaborative interaction with native speakers of Spanish in the US. Language Learning \& Technology, 8(1), 83-100.

Markey, A. (2007). Using the Moodle platform in online exchanges. In R. O'Dowd (Ed.), Online intercultural exchange: An introduction for foreign language teachers (pp. 264-268). Clevedon, UK: Multilingual Matters.

Meguro, A., \& Bryant, T. (2010). Finding language partners in unexpected places: Skype and social networking for USA-Japan telecollaboration. In S. Guth \& F. Helm (Eds.), Telecollaboration 2.0: Language, literacies and intercultural learning in the 21st century (pp. 453-463). Bern, Switzerland: Peter Lang.

Miguela, A. D. (2007). Models of telecollaboration (3): eTwinning. In R. O'Dowd (Ed.), Online intercultural exchange: An introduction for foreign language teachers (pp. 85-104). Clevedon, UK: Multilingual Matters. 
Müller-Hartmann, A. (2006). Learning how to teach intercultural communicative competence via telecollaboration: A model for language teacher education. In J. A. Belz \& S. L. Thorne (Eds.), Internet-mediated intercultural foreign language education (pp. 63-84). Boston, MA: Heinle.

Müller-Hartmann, A. (2007). Teacher role in telecollaboration: Setting up and managing exchanges. In R. O'Dowd (Ed.), Online intercultural exchange: An introduction for foreign language teachers (pp. 167-192). Clevedon, UK: Multilingual Matters.

O'Dowd, R. (2005). Negotiating sociocultural and institutional contexts: The case of SpanishAmerican telecollaboration. Language and Intercultural Communication, 5(1), 40-56.

O'Dowd, R. (2006). The use of videoconferencing and email as mediators of intercultural student ethnography. In J. A. Belz \& S. L. Thorne (Eds.), Internet-mediated intercultural foreign language education (pp. 86-120). Boston, MA: Heinle.

O'Dowd, R. (Ed.). (2007). Online intercultural exchange: An introduction for foreign language teachers. Clevedon, UK: Multilingual Matters.

O'Dowd, R., \& Ritter, M. (2006). Understanding and working with "failed communication" in telecollaborative exchanges. CALICO Journal, 23(3), 623-642.

O'Rourke, B. (2007). Models of telecollaboration (1): eTandem. In R. O'Dowd (Ed.), Online intercultural exchange: An introduction for foreign language teachers (pp. 41-61). Clevedon, UK: Multilingual Matters.

Rathje, S. (2007). Intercultural competence: The status and future of a controversial concept. Language and Intercultural Communication, 7(4), 254-268.

Reeder, K., Macfadyen, L. P., Roche, J., \& Chase, M. (2004). Negotiating cultures in cyberspace: Participation patterns and problematics. Language, Learning \& Technology, 8(2), 88-105.

Robinson, P. (Ed.). (2011). Task-based language learning. West Sussex, UK: Wiley-Blackwell.

Samuda, V., \& Bygate, M. (2008). Tasks in second language learning. Basingstoke, UK: Palgrave Macmillan.

Seidlhofer, B., \& Widdowson, H. (2009). Accommodation and the idiom principle in English as a lingua franca. In K. Murata \& J. Jenkins (Eds.), Global Englishes in Asian contexts: Current and future debates (pp. 26-39). Basingstoke, UK: Palgrave Macmillan.

Smith, L. (2009). Dimensions of understanding in cross-cultural communication. In K. Murata \& J. Jenkins (Eds.), Global Englishes in Asian contexts: Current and future debates (pp. 17-25). Basingstoke, UK: Palgrave Macmillan.

Stockwell, G. (2010). Effects of multimodality in computer-mediated communication tasks. In M. Thomas \& H. Reinders (Eds.), Task-based language learning and teaching with technology (pp. 83-104). London, UK: Continuum.

Tian, J., \& Wang, Y. (2010). Taking language learning outside the classroom: Learners' perspectives of eTandem learning via Skype. Innovation in Language Learning and Teaching, 4(3), 181-197.

Ware, P. (2005). "Missed" communication in online communication: Tensions in a GermanAmerican telecollaboration. Language Learning \& Technology, 9(2), 64-89.

Warschauer, M., \& Healey, D. (1998). Computers and language learning: An overview. Language Teaching, 31(2), 57-71.

Willis, J. (1996). A framework for task-based learning. Harlow, UK: Longman.

Willis, D., \& Willis, J. (2007). Doing task-based teaching. Oxford, UK: Oxford University Press. 


\section{Appendix A}

Use this guide to type your first email to your epal.

Hello,

My name is . My (friends / classmates) just call me I study . It is (very / fairly) . I (want / plan / promise) to (write to you / mail you / send you mail) this semester. I hope you will too.

I am sending you a (photo / picture) with this (email / letter). There are three in the picture, me and two However, I am not going to tell you which is me. I want you to guess. Please ask me five questions and I will give you five clues. So, please ask me one question about my face, one question about my hair, one question about my clothes, one question about my body and one question about my personality.

I am looking forward to your (mail / reply).

Bye,

\section{Appendix B}

Use this guide to type a reply to your epal.

Hello,

Thank you for your . Everybody looks very in the . I wrote five questions for you, one question about your face, one question about your hair, one question about your clothes, one question about your body and one question about your personality.

These are my questions.

1. Wh ...

2. Wh ...

3.

4.

5.

I am looking forward to your (mail / reply), 